\title{
Effect of quercetin on postprandial glucose excursion after mono- and disaccharides challenge in normal and diabetic rats
}

\author{
Saad Abdulrahman Hussain ${ }^{1^{*}}$, Zheen Aorahman Ahmed ${ }^{2}$, Taha Othman Mahwi $^{3}$, \\ Tavga Ahmed Aziz ${ }^{4}$ \\ ${ }^{1}$ Department of Pharmacology and Toxicology, College of Pharmacy, University of Baghdad, Baghdad, Iraq; \\ *Corresponding Author: saad alzaidi@yahoo.com \\ ${ }^{2}$ Department of Pharmacology, College of Medicine, University of Sulaimani, Kurdistan, Iraq \\ ${ }^{3}$ Department of Medicine, College of Medicine, University of Sulaimani, Kurdistan, Iraq \\ ${ }^{4}$ Department of Pharmacology and Toxicology, College of Pharmacy, University of Sulaimani, Kurdistan, Iraq
}

Received 28 October 2011; revised 30 November 2011; accepted 16 December 2011

\section{ABSTRACT}

Postprandial hyperglycemia is a major risk factor for diabetic complications leading to disabilities and mortality in diabetics. Quercetin, a flavonoid, has been tried in traditional medicine for treating diabetes. The present study was designed to evaluate the potential of quercetin to control postprandial blood glucose level after maltose and glucose loading in normal and STZinduced diabetic rats. Normal male Albino wistar rats and STZ-induced diabetic rats were treated with 300 and $600 \mathrm{mg} / \mathrm{kg}$ quercetin orally to evaluate the effect on postprandial hyperglycemia after carbohydrate loading, using acarbose as comparator. The results clearly showed ameliorated postprandial hyperglycemia due to the use of quercetin (300 and $600 \mathrm{mg} / \mathrm{kg}$ ), it significantly dampened the postprandial hyperglycemia by $32.0 \%$ and $64.0 \%$ respectively, in maltose loaded diabetic rats, and $30.3 \%$ after 300 $\mathrm{mg} / \mathrm{kg}$ dose in normal rats, compared to control; while acarbose produced $51 \%$ and $54 \%$ decrease in this respect in the two models respecttively. Quercetin in $600 \mathrm{mg} / \mathrm{kg}$ dose produces significantly more reduction in postprandial hyperglycemia compared to acarbose, while in rats that received glucose and quercetin, postprandial hyperglycemia was not significantly affected. In conclusion, quercetin effectively suppresses postprandial hyperglycemia in STZ-induced diabetic rats loaded with maltose, which may be attributed to $\alpha$-glucosidase inhibition. Quercetin could be used as a potential supplement for treating postprandial hyperglycemia.
Keywords: Quercetin; Postprandial Hyperglycemia; Diabetes; $\alpha$-Glucosidase; Rats

\section{INTRODUCTION}

In individuals with type II diabetes, nutrient intake related first-phase insulin response is severely diminished or absent, resulting in persistently elevated postprandial glucose (PPG) throughout most of the day [1]. This is due to the delayed peak insulin levels which are insufficient to control PPG excursions adequately [2]. Postprandial hyperglycemia is a major risk factor for microand macro-vascular complications associated with diabetes [3], and controlling postprandial plasma glucose level is critical during early treatment of diabetes mellitus and in reducing chronic vascular complications [4]. The acute glucose fluctuations during the postprandial period exhibits a more specific triggering effect on oxidative stress than chronic sustained hyperglycemia which suggests that therapy in type II diabetes should target not only hemoglobin Alc and mean glucose concentrations but also acute glucose excursions [5]. $\alpha$-glucosidase inhibitors delay breakdown of carbohydrate in small intestine and diminish postprandial blood glucose excursion in diabetic subjects [6], and thus have a lowering effect on postprandial blood glucose and insulin levels. Commercially available $\alpha$-glucosidase inhibitors such as acarbose, miglitol and voglibose are widely used to treat patients with type 2 diabetes [7]. Several $\alpha$-glucosidase inhibitors have been isolated from medicinal plants to develop as an alternative drug with increased potency and lesser adverse effects than the existing drugs [8]. Quercetin, a flavonoid antioxidant, is a leading potential candidate for treating DM [9]. The long-term consumption of quercetin appears to control blood glucose levels 
in streptozotocin (STZ)-induced diabetic animals [10,11]. It has been suggested that quercetin protects the pancreas against oxidative stress in STZ-treated animals, improveing hyperglycemia [12]. Quercetin has been reported to lower plasma glucose, normalize glucose tolerance tests, preserve pancreatic $\beta$-cell integrity and function, and help protect against diabetes-induced declines in cognition, mood, and renal function in rat models of diabetes $[13,14]$. Quercetin also appears to be beneficial in diabetic neuropathy and neuropathic pain in streptozotocin (STZ)-induced diabetic rats [15]. It has also been reported that QE inhibits $\alpha$-glucosidase activity in vitro $[16,17]$; however, no direct in vivo evidence available for its effect on postprandial hyperglycemia after disaccharides load. The present project was designed to evaluate the effect of quercetin on postprandial glucose excursion associated with disaccharide and monosaccharide challenge in normal and diabetic rats.

\section{MATERIALS AND METHODS}

\subsection{Experimental Animals}

Sixty six adult male albino Wistar rats were maintained during the experiments in the animal house, College of Pharmacy, University of Sulaimani; 12 - 13 weeks old rats, weighing 160 - $210 \mathrm{~g}$ were kept in a room with a 12-hr light/12-hr dark cycle at $25^{\circ} \mathrm{C} \pm 2{ }^{\circ} \mathrm{C}$, fed with standard rodent diet (National Center for Drug Research and Quality Control, Baghdad) and water ad libitum. All animal procedures were approved by the ethical committee in accordance with the institutional Animal Ethics Committee.

\subsection{Induction of Diabetes}

Thirty six rats previously fasted for $16 \mathrm{hr}$ were given single intraperitoneal injection of $45 \mathrm{mg} / \mathrm{kg}$ body wt. streptozotocin (Sigma, USA) dissolved in freshly prepared citrate buffer $(0.1 \mathrm{M}, \mathrm{pH} 4.5)$. Animals with fasting blood glucose over $250 \mathrm{mg} / \mathrm{dl}$, three days after streptozotocin (STZ) administration were considered diabetic and they received treatment similar to that of normal rats.

\subsection{Maltose Loading in Normal Rats}

Total of eighteen normal rats were allocated into three groups of six animals each. After 16 hours fasting, group 1 had received maltose $(2 \mathrm{~g} / \mathrm{kg}$; p.o.) as the normal control; group 2 was coadministered with maltose $(2 \mathrm{~g} / \mathrm{kg}$; p.o.) and quercetin dihydrate (Xia'n Co, China) (300 $\mathrm{mg} / \mathrm{kg}$ body wt; p.o.); group 3 was coadministered with maltose ( $2 \mathrm{~g} / \mathrm{kg}$; p.o.) and acarbose (Bayer, Germany) (5 $\mathrm{mg} / \mathrm{kg}$; p.o.). The selected doses of quercetin and acarbose were determined to be safe based on previous studies $[18,19]$. Blood glucose level was measured before and 30, 60, 90 and 120 minutes after the maltose loading using a glucometer (Beurer Medical TM GmbH, Germany). The change in blood glucose from the basal level after the maltose load was analyzed and represented as delta blood glucose.

\subsection{Maltose Loading in Diabetic Rats}

Total of 24 diabetic rats were allocated into 3 groups of six animals each. Group 1 had received maltose (2 $\mathrm{g} / \mathrm{kg}$; p.o.) as the diabetic control; groups 2 and 3 were coadministered with maltose $(2 \mathrm{~g} / \mathrm{kg}$; p.o.) and quercetin dihydrate (300 and $600 \mathrm{mg} / \mathrm{kg}$; p.o., respectively); group 4 was coadministered with maltose $(2 \mathrm{~g} / \mathrm{kg} ;$ p.o. $)$ and acarbose $(5 \mathrm{mg} / \mathrm{kg}$; p.o.). Blood glucose level was measured as previously indicated.

\subsection{Glucose Loading in Normal Rats}

Total of twelve normal rats were allocated into two groups of six animals each. After 16 hours fasting, group 1 had received glucose ( $2 \mathrm{~g} / \mathrm{kg}$; p.o.) as the control, while group 2 was coadministered with glucose $(2 \mathrm{~g} / \mathrm{kg}$; p.o.) and quercetin dihydrate $(300 \mathrm{mg} / \mathrm{kg}$; p.o.). Blood glucose level was measured as mentioned previously.

\subsection{Glucose Loading in Diabetic Rats}

Total of twelve diabetic rats were allocated into two groups of six animals each. After 16 hours fasting, group 1 had received glucose ( $2 \mathrm{~g} / \mathrm{kg}$; p.o.) as diabetic control; group 2 was coadministered with glucose $(2 \mathrm{~g} / \mathrm{kg}$; p.o.) and quercetin dihydrate $(300 \mathrm{mg} / \mathrm{kg}$; p.o.). Blood glucose level was measured as indicated before.

\subsection{Statistical Analysis}

The delta blood glucose levels were expressed as mean \pm SE for six animals in each group. Statistical analysis was performed using t-test or one-way analysis of variance (ANOVA) followed by Dunnett's Multiple Comparison Test using GraphPad Prism 5 for Windows software (GraphPad Software, Inc., USA). $P$-values less than 0.05 were considered to be statistically significant.

\section{RESULTS}

\subsection{Maltose Loading in Normal Rats}

Postprandial blood glucose variation was measured after loading maltose to the normal rats with and without coadministration of quercetin. In the control group, blood glucose level increased by an average of $55 \mathrm{mg} / \mathrm{dl}$ at 30 minutes after the maltose load, while the standard comparator, acarbose produces $22.5 \mathrm{mg} / \mathrm{dl}$ decrease at the same time. In the group that received $300 \mathrm{mg} / \mathrm{kg}$ quercetin along with maltose, the 30 minutes post-load glu- 
cose level increased only by $37 \mathrm{mg} / \mathrm{dl}$ on an average (Figure 1). This indicates the potency of quercetin to significantly suppress high maltose diet associated postprandial glucose elevation. Compared to control, the whole glycemic response is reduced by $32.7 \%$ on quercetin, while acarbose showed $59 \%$ decrease in glucose elevation which is significantly higher compared to both other groups (Figure 2).

\subsection{Maltose Loading in Diabetic Rats}

As quercetin exhibited appreciable postprandial blood glucose lowering effect in normal rats, we evaluated its inhibitory effect on STZ-induced diabetic rats. In the control group, blood glucose level increased to an average of $370 \mathrm{mg} / \mathrm{dl}$ above the basal level $30 \mathrm{~min}$ after maltose loading and decreased thereafter (Figure 3). However, the rise of the post-load blood glucose has been significantly impeded in a dose dependent pattern on coadministering quercetin with maltose at different doses (300 and $600 \mathrm{mg} / \mathrm{kg}$ ). Similar kind of suppression effect was observed in the group that received acarbose ( 5 $\mathrm{mg} / \mathrm{kg}$ ) as the positive control along with maltose. Compared to control, the whole glycemic response is reduced

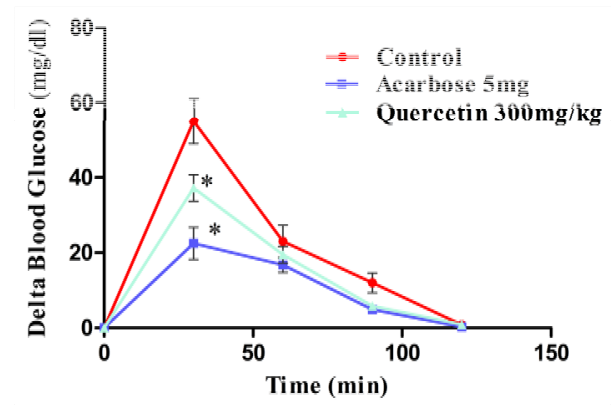

Figure 1. Effect of single oral dose of quercetin and acarbose on blood glucose after maltose loading in normal rats. The glycemic response curve in normal rats after maltose challenge. ${ }^{*}$ Significantly different compared to control $(P<0.05)$.

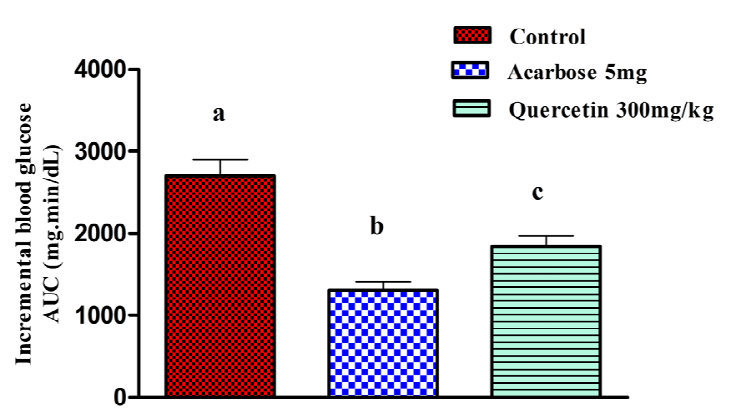

Figure 2. Effect of quercetin and acarbose on the incremental blood glucose $\mathrm{AUC}_{0-120} \mathrm{~min}$ in normal rats after maltose load; values with non-identical superscripts ( $\mathrm{a}, \mathrm{b}$, c) are considered significantly different $(P<0.05)$. by $29.2 \%, 59 \%$ and $51.3 \%$ when treated with 300,600 $\mathrm{mg} / \mathrm{kg}$ of quercetin and $5 \mathrm{mg} / \mathrm{kg}$ of acarbose, respectively (Figure 4).

\subsection{Glucose Loading in Normal Rats}

To confirm that the observed suppression of postprandial glucose, reported during maltose loading is due to the inhibition of $\alpha$-glucosidase, postprandial blood glucose variation was measured after loading glucose to the normal rats with and without the coadministration of quercetin. In control group, blood glucose level increased by an average of $26 \mathrm{mg} / \mathrm{dl}$ at $30 \mathrm{~min}$ after the glucose load. In the group that received $300 \mathrm{mg} / \mathrm{kg}$ quercetin along with glucose, the 30 minutes post-load glucose level increased by $22 \mathrm{mg} / \mathrm{dl}$ on an average (Figure 5), which shows that the glucose absorption is not significantly affected due to the use of quercetin (Figure 6).

\subsection{Glucose Loading in Diabetic Rats}

To evaluate the effect of quercetin on glucose toler-

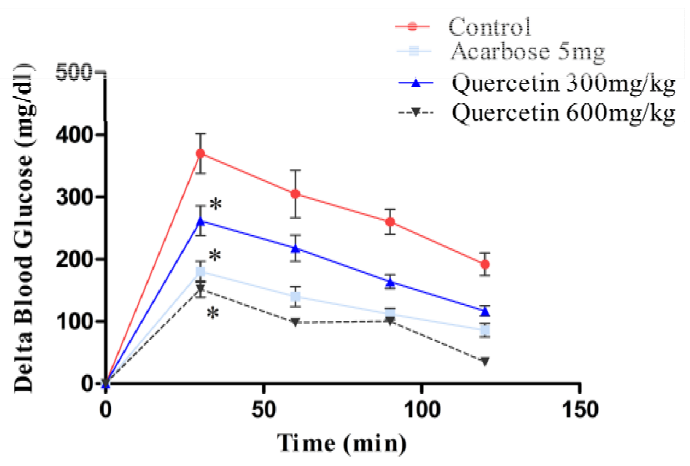

Figure 3. Effect of single oral dose of 300 and 600 $\mathrm{mg} / \mathrm{kg}$ quercetin and acarbose on blood glucose after maltose loading in diabetic rats. The glycemic response curve in diabetic rats after maltose challenge. * Significantly different compared to control $(P<$ $0.05)$.

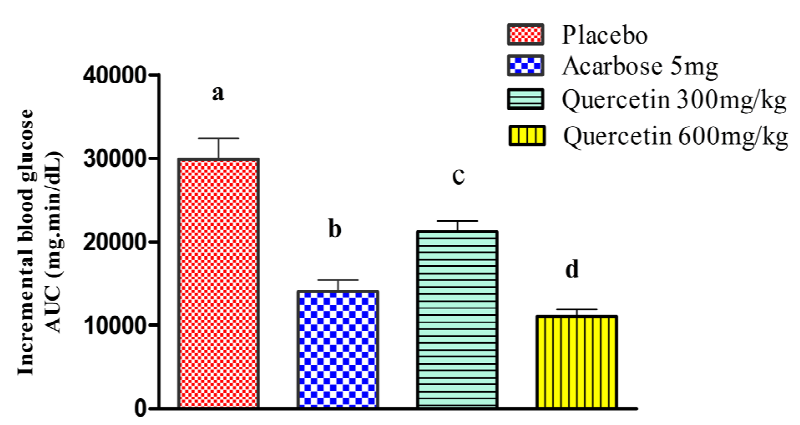

Figure 4. Effect of 300 and $600 \mathrm{mg} / \mathrm{kg}$ single oral dose of quercetin and $5 \mathrm{mg}$ acarbose on the incremental blood glucose $\mathrm{AUC}_{0-120}$ min in diabetic rats after maltose load; values with non-identical superscripts $(a, b, c, d)$ are considered significantly different $(P<0.05)$. 


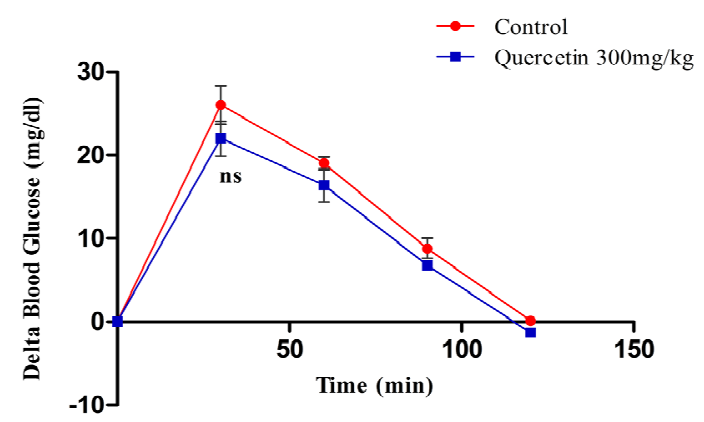

Figure 5. Effect of single oral dose of $300 \mathrm{mg} / \mathrm{kg}$ quercetin on blood glucose after glucose loading in normal rats. The glycemic response curve in normal rats after glucose challenge. ns $=$ non-significantly different compared to control $(P>0.05)$.

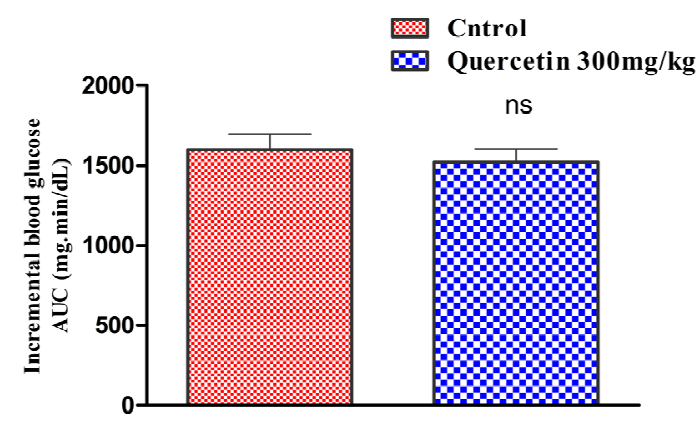

Figure 6. Effect of quercetin on the incremental blood glucose $\mathrm{AUC}_{0-120}$ min in normal rats after glucose load; ns $=$ non-significantly different compared to control $(P$ $>0.05)$.

ance in diabetic condition and to elucidate whether the observed postprandial glucose suppression is mostly due to $\alpha$-glucosidase inhibition, postprandial blood glucose variation was measured after glucose loading to the diabetic rats with and without coadministration of $300 \mathrm{mg} / \mathrm{kg}$ quercetin. In the control group, blood glucose level increased by an average of $305 \mathrm{mg} / \mathrm{dl}$ at $30 \mathrm{~min}$ after the glucose load. In the group that received quercetin along with glucose, the $30 \mathrm{~min}$ post-load glucose level increased by $312 \mathrm{mg} / \mathrm{dl}$ (Figure 7), which shows that glucose absorption is not significantly affected due to administration of quercetin, as shown by the non-significant differences in AUC of postprandial glucose spike compared to control (Figure 8).

\section{DISCUSSION}

Diabetic individuals are at an increased risk of developing microvascular complications (retinopathy, nephropathy, and neuropathy) and cardiovascular disease. Abnormalities in insulin and glucagon secretion, hepatic glucose uptake, suppression of hepatic glucose production, and peripheral glucose uptake contribute to higher and more prolonged postprandial glycemic (PPG) excur-

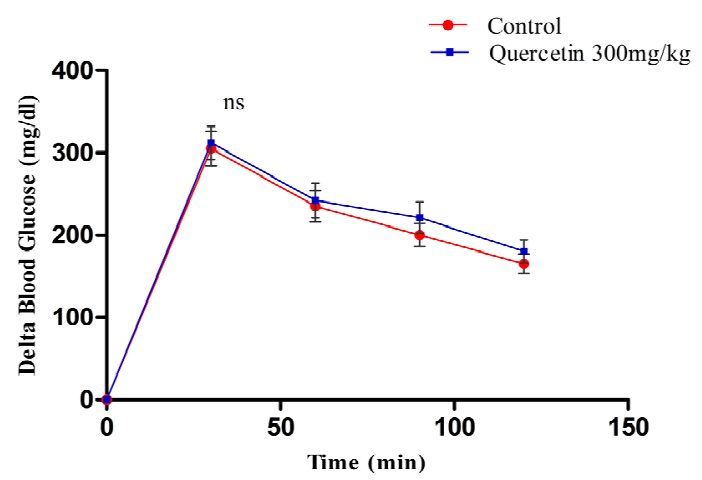

Figure 7. Effect of single oral dose of $300 \mathrm{mg} / \mathrm{kg}$ quercetin on blood glucose after glucose loading in diabetic rats. The glycemic response curve in diabetic rats after glucose challenge. ns $=$ non-significantly different compared to control $(P>0.05)$.

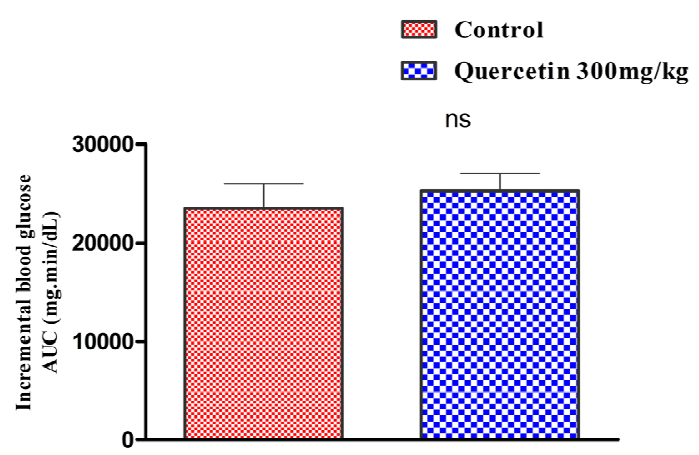

Figure 8. Effect of quercetin on the incremental blood glucose $\mathrm{AUC}_{0-120} \mathrm{~min}$ in diabetic rats after glucose load; ns $=$ non-significantly different compared to control $(P>0.05)$.

sions than in non diabetic individuals [2]. Elevated PPG even in the absence of fasting hyperglycemia increases the risk of cardiovascular diseases and it is the most common cause of death among the people with diabetes. Acute hyperglycemia induces endothelial dysfunction by generating oxidative stress resulting in impaired vasodilatation [20]. Also, postprandial spikes can result in microvascular damage through oxidation of low density lipoprotein (LDL) and other pro-atherogenic mechanisms [21]. Diet rich in carbohydrate causes sharp rise in the blood glucose level as the complex carbohydrates in the food is rapidly absorbed in the intestine aided by the $\alpha$-glucosidase enzyme which breaks disaccharides into absorbable monosaccharides [22]. $\alpha$-glucosidase inhibitor inhibits the disaccharide digestion and impedes the postprandial glucose excursion to enable overall smooth glucose profile [23]. According to the available evidence about the positive in vitro inhibitory effects of quercetin on $\alpha$-glucosidase activity [16,17], we evaluate its effect on postprandial hyperglycemia associated with carbohydrate challenge using rats as experimental model. The 
study design is based on the hypothesis that on administering quercetin to the diabetic rats, postprandial glucose excursion associated maltose challenge gets stymied but not during glucose challenge. Because, the $\alpha$-glucosidase action is crucial for the digestion of maltose without which this disaccharide would not be rapidly converted into absorbable glucose. As expected, quercetin blunted acute postprandial hyperglycemic spike in normal rats loaded with maltose but not with glucose. Subsequently, the postprandial hyperglycemia amelioration of quercetin was evaluated in the STZ-induced diabetic rats. In general, the postprandial glucose level of STZ-induced diabetic rat is poorly controlled due to impaired insulin production [24]. It has been reported that chronic consumption of quercetin $(0.1 \%$ of diet $)$ decreased blood glucose in STZ-treated rats [10]. Moreover, quercetin protected pancreatic $\beta$ cells from oxidative stress and damage, resulting in increased insulin secretion in STZtreated rats [12]. However, in our study, coadministration of maltose along with a single dose of quercetin (300 $\mathrm{mg} / \mathrm{kg}$ and $600 \mathrm{mg} / \mathrm{kg}$ ) to the diabetic rats attenuated the increase in postprandial hyperglycemia in a dose dependent manner. On the other hand, control animals showed an extremely high level of blood glucose that has been staying high even two hours after the maltose load. One of the reasons for observing the suppressed postprandial glucose level in diabetic rats could be due to the damping effect of quercetin on the maltose digestion at small intestine. The standard drug, acarbose similarly suppressed the postprandial glucose level; this effect support similar results obtained with different doses of quercetin in starch loaded rats [25]. As the observed postprandial glucose suppression could also be possible because of the secretagogue activity and insulin sensitizing property of quercetin, we have evaluated the effect of quercetin on glucose loading in normal and diabetic rats. Quercetin did not suppress the postprandial hyperglycemia associated with glucose loading significantly but on maltose loading, which indicates that the major mechanism of action of postprandial glucose suppression may be exhibited by inhibition of $\alpha$-glucosidase. Previous reports on $\alpha$-glucosidase inhibitors isolated from medicinal plants showed that many potential inhibitors belong to flavonoid glycoside class, which has the characteristic structural features to inhibit $\alpha$-glucosidase enzyme $[26,27]$. Based on these results, we can speculate that oral administration of flavonoid glycosides might have contributed to the $\alpha$-glucosidase inhibitory effect and control of postprandial hyperglycemia.

\section{CONCLUSION}

The results of the present study indicated that orally administered quercetin suppresses, in a dose dependent pattern, maltose-induced postprandial blood glucose spikes in both normal and diabetic rats.

\section{ACKNOWLEDGEMENTS}

The present data were abstracted from a $\mathrm{PhD}$ thesis submitted to the Department of Pharmacology, College of Medicine, University of Sulaimani, and totally supported by Kurdistan regional government. The authors gratefully thank College of Pharmacy, University of Sulaimani, and College of Pharmacy, University of Baghdad for technical support.

\section{REFERENCES}

[1] Parkin, C.G. and Brooks, N. (2002) Is postprandial glucose control important? Is it practical in primary care settings? Clinical Diabetes, 20, 71-76.

doi:10.2337/diaclin.20.2.71

[2] ADA (2001) Postprandial blood glucose. Diabetes Care, 24, 775-778. doi:10.2337/diacare.24.4.775

[3] Hanefeld, M., Schmechel, H., Julius, U. and Schwanebeck, U. (1996) Determinants for coronary heart disease in non-insulin-dependent diabetes mellitus: Lessons from the diabetes intervention study. Diabetes Research and Clinical Practice, 30, 67-70. doi:10.1016/S0168-8227(96)80040-4

[4] Ortiz-Andrade, R.R., Garcia-Jimenez, S., Castillo-Espana, P., Ramirez-Avila, G., Villalobos-Molina, R. and EstradaSoto, S. (2007) alpha-Glucosidase inhibitory activity of the methanolic extract from Tournefortia hartwegiana: An anti-hyperglycemic agent. Journal of Ethnopharmacology, 109, 48-53.

[5] Monnier, L. and Colette, C. (2006) Contributions of fasting and postprandial glucose to hemoglobin A1c. Endocrinology Practice, 12, 42-46.

[6] Van de Laar, F.A. (2008) Alpha-glucosidase inhibitors in the early treatment of type 2 diabetes. Vascular Health Risk Management, 4, 1189-1195.

[7] Van de Laar, F.A., Lucassen, P.L., Akkermans, R.P., van de Lisdonk, E.H., et al. (2005) Alpha-glucosidase inhibitors for patients with type 2 diabetes: Results from a Cochrane systematic review and meta-analysis. Diabetes Care, 28, 154-163. doi:10.2337/diacare.28.1.154

[8] Matsuda, H., Nishida, N. and Yoshikawa, M. (2002) Antidiabetic principles of natural medicines. V. Aldose reductase inhibitors from Myrcia multiflora DC. (2): Structures of myrciacitrins III, IV, and V. Chemistry and Pharmacy Bulletin, 50, 429-431. doi:10.1248/cpb.50.429

[9] Adewole, S.O., Caxton-Martins, E.A. and Ojewole, J.A.O. (2006) Protective effect of quercetin on the morphology of pancreatic $\beta$-cells of streptozotocin-treated diabetic rats. African Journal of Traditional Complementary and Alternative Medicine, 4, 64-74.

[10] Shetty, A.K., Rashmi, R., Rajan, M.G.R., Sambaiah, K. and Salimath P.V. (2004) Antidiabetic influence of quercetin in streptozotocin-induced diabetic rats. Nutrition Research, 24, 373-381.

doi:10.1016/j.nutres.2003.11.010 
[11] Anjaneyulu, M. and Chopra, K. (2004) Quercetin, an anti-oxidant bioflavonoid, attenuates diabetic nephropathy in rats. Clinical and Experimental Pharmacology and Physiology, 31, 244-248. doi:10.1111/j.1440-1681.2004.03982.x

[12] Coskun, O., Kanter, M., Korkmaz, A. and Oter, S. (2005) Quercetin, a flavonoid antioxidant, prevents and protects streptozotocin-induced oxidative stress and $\beta$-cell damage in rat pancreas. Pharmacological Research, 51, 117-123. doi:10.1016/j.phrs.2004.06.002

[13] Kobori, M., Masumoto, S., Akimoto, Y. and Takahashi, Y. (2009) Dietary quercetin alleviates diabetic symptoms and reduces streptozotocin-induced disturbance of hepatic gene expression in mice. Molecular Nutrition and Food Research, 53, 859-868. doi:10.1002/mnfr.200800310

[14] Youl, E., Bardy, G., Magous, R., Cros, G., Sejalon, F., Virsolvy, A., et al. (2010) Quercetin potentiates insulin secretion and protects INS-1 pancreatic $\beta$-cells against oxidative damage via the ERK1/2 pathway. British Journal Pharmacology, 161, 799-814. doi:10.1111/j.1476-5381.2010.00910.x

[15] Anjaneyulu, M. and Chopra, K. (2004) Quercetin attenuates thermal hyperalgesia and cold allodynia in STZ induced diabetic rats. Indian Journal of Experimental Biology, 42, 766-769.

[16] Ishikawa, A., Yamashita, H., Hiemori, M., Inagaki, E., Kimoto, M., Okamoto, M., et al. (2007) Characterization of inhibitors of postprandial hyperglycemia from the leaves of Nerium indicum. Journal of Nutrition Science and Vitaminology, 53, 166-173. doi:10.3177/jnsv.53.166

[17] Jo, S.H., Ka, E.H., Lee, H.S., Apostolidis, E., Jang, H.D. and Kwon, Y.I. (2009) Comparison of antioxidant potential and rat intestinal $\alpha$-glucosidases inihibitory activities of quercetin, rutin, and isoquercetin. International Journal of Applied Research and Natural Products, 2, 52-60.

[18] Meng, X., Maliakal, P., Lu, H., Lee, M.J. and Yang, C.S. (2004) Urinary and plasma levels of resveratrol and quercetin in humans, mice, and rats after ingestion of pure compounds and grape juice. Journal of Agriculture and Food Chemistry, 52, 935-942. doi:10.1021/jf030582e
[19] Sima, A.A. and Chakrabarti, S. (1992) Long-term suppression of postprandial hyperglycaemia with acarbose retards the development of neuropathies in the BB/W-rat. Diabetologia, 35, 325-330. doi:10.1007/BF00401199

[20] Monnier, L., Mas, E., Ginet, C., Michel, F., Villon, L., Cristol, J. P. and Colette, C. (2006) Activation of oxidative stress by acute glucose fluctuations compared with sustained chronic hyperglycemia in patients with type 2 diabetes. Journal of American Medical Association, 295, 1681-1687. doi:10.1001/jama.295.14.1681

[21] Aryangat, A.V. and Gerich, J.E. (2010) Type 2 diabetes: Postprandial hyperglycemia and increased cardiovascular risk. Vascular Health Risk Management, 6, 145-155.

[22] Dahlqvist, A. and Borgstrom, B. (1961) Digestion and absorption of disaccharides in man. Biochemical Journal, 81, 411-418.

[23] Hogan, S., Zhang, L., Li, J., Sun, S., Canning, C. and Zhou, K. (2010) Antioxidant rich grape pomace extract suppresses postprandial hyperglycemia in diabetic mice by specifically inhibiting alpha-glucosidase. Nutrition and Metabolism, 7, 71. doi:10.1186/1743-7075-7-71

[24] Pospisilik, J.A., Martin, J., Doty, T., Ehses, J.A., Pamir, N., Lynn, F.C., et al. (2003) Dipeptidyl peptidase IV inhibitor treatment stimulates beta-cell survival and islet neogenesis in streptozotocin-induced diabetic rats. Diabetes, 52, 741-750. doi:10.2337/diabetes.52.3.741

[25] Kim, J.H., Kang, M.J., Choi, H.N., Jeong, S.M., Lee, Y.M. and Kim, J.I. (2011) Quercetin attenuates fasting and postprandial hyperglycemia in animal models of diabetes mellitus. Nutrition Research Practice, 5, 107-111.

[26] Lee, S.S., Lin, H.C. and Chen, C.K. (2007) Acylated flavonol monorhamnosides, alpha-glucosidase inhibitors, from Machilus philippinensis. Phytochemistry, 69, 23472353. doi:10.1016/j.phytochem.2008.06.006

[27] Jong-Anurakkun, N., Bhandari, M.R. and Kawabata, J. (2007) Alpha-glucosidase inhibitors from Devil tree (Alstonia scholaris). Food Chemistry, 103, 1319-1323. doi:10.1016/j.foodchem.2006.10.043 